\title{
PENGGUNAAN SIMULASI VIRTUAL PADA PEMBELAJARAN FISIKA UNTUK MENINGKATKAN HIGHER ORDER THINKING SKILL (HOTS) SISWA : META-ANALISIS
}

\author{
Miftahul Khirana Anisa, Niki Dian Permana P*, Theresia Lidya Nova \\ Program Studi Tadris IPA, Universitas Islam Negeri Sultan Syarif Kasim Riau \\ Jalan HR, Soebrantas Km. 15 No. 155, Indonesia \\ e-mail": niki.dian.permana@uin-suska.ac.id
}

\begin{tabular}{c|c|c|c}
\hline Diterima 12 Juli 2020 & Direvisi 3 Agustus 2020 & Disetujui 21 Agustus 2020 & Dipublikasikan 31 Agustus 2020 \\
\hline \multicolumn{4}{c}{ https://doi.org/10.33369/jkf.3.2.163-170 } \\
\hline
\end{tabular}

\begin{abstract}
ABSTRAK
Penelitian ini bertujuan untuk menganalisis penggunaan simulasi virtual untuk meningkatkan Higher Order Thinking Skills (HOTS) siswa pada pembelajaran Fisika. Metode penelitian yang digunakan adalah metode kuantitatif. Desain yang digunakan yaitu meta-analisis. Meta-analisis adalah penelitian yang dilakukan dengan cara merangkum, mereviu dan menganalisis data peneliti dari beberapa hasil penelitian sebelumnya. Pengumpulan data dilakukan dengan cara mencari artikel yang berkaitan dengan penggunaan simulasi virtual untuk meningkatkan Higher Order Thinking Skills siswa pada jurnal nasional yang terakreditasi pada sinta 1 hingga sinta 4 dan beberapa jurnal internasional bereputasi. Sampel yang digunakan berupa 20 artikel jurnal. Hasil penelitian ini menunjukan bahwa penggunaan simulasi virtual dapat meningkatkan Higher Order Thinking Skills (HOTS) siswa pada pembelajaran Fisika.

Kata kunci : Meta-analisis, Simulasi Virtual, HOTS, Pembelajaran Fisika
\end{abstract}

\begin{abstract}
This study aimed to analyze the use of virtual simulations to improve students' Higher Order Thinking Skills (HOTS) in learning Physics. The research method used was a quantitative method. The design used is meta-analysis. Meta-analysis was research conducted by summarizing, reviewing and analyzing researchers' data from several previous research results. Data collection was done by searching for articles relating to the use of virtual simulations to improve students' Higher Order Thinking Skills in national journals that are accredited in SINTA 1 to SINTA 4 and several reputable international journals. The sample used was in the form of 20 journal articles. The results of this study indicated that the use of virtual simulations can improve students' Higher Order Thinking Skills (HOTS) in learning physics.
\end{abstract}

Keywords : Meta-analysis, Virtual Simulation, HOTS, Physics Learning

\section{PENDAHULUAN}

Menurut Undang-Undang Nomor 20 Tahun 2003 tentang Sistem Pendidikan Nasional, Pasal 1 angka 1 menyatakan bahwa "pendidikan adalah usaha sadar dan terencana untuk mewujudkan suasana belajar dan proses pembelajaran agar peserta didik secara aktif mengembangkan potensi dirinya untuk memiliki kekuatan spiritual keagamaan, pengendalian diri, kepribadian, kecerdasan, akhlak mulia, serta keterampilan yang diperlukan dirinya, masyarakat, bangsa dan negara. Proses pembelajaran pada satuan pendidikan diselenggarakan secara interaktif, inspiratif, menyenangkan, menantang, memotivasi peserta didik untuk berpartisipasi aktif, serta memberikan ruang yang cukup bagi prakarsa, kreativitas, dan kemandirian sesuai dengan bakat, minat, dan perkembangan fisik serta psikologis peserta didik. Untuk itu setiap satuan pendidikan melakukan perencanaan pembelajaran, pelaksanaan proses pembelajaran serta penilaian proses pembelajaran untuk meningkatkan efisiensi dan efektivitas ketercapaian kompetensi lulusan" (1).

Ilmu Pengetahuan Alam (IPA) memiliki salah satu cabang ilmu yang mendasari perkembangan kemajuan teknologi dan konsep hidup harmonis dengan alam yaitu Fisika. Fenomena alam dipelajari dalam ilmu fisika agar manusia dapat hidup selaras dengan alam berdasarkan hukum-hukum alam yang ada. alam. Pembelajaran fisika ini mempunyai tujuan yang 
telah dirumuskan oleh pemerintah untuk dilakukan dalam proses pembelajaran pada satuan pendidikan.

Pembelajaran Fisika mempunyai tujuan yaitu untuk mengembangkan pengalaman agar dapat merumuskan masalah, mengajukan dan menguji hipotesis melalui percobaan, mengumpulkan, mengolah, dan menafsirkan data, dan dapat menyajikan hasil percobaan secara lisan dan tertulis dengan menggunakan konsep dan prinsip fisika untuk menjelaskan berbagai peristiwa alam. Selain itu pembelajaran fisika mampu meningkatkan kemampuan bernalar dalam berpikir kritis dan kreatif dengan menggunakan konsep dan prinsip fisika untuk menjelaskan berbagai peristiwa alam dan menyelesaian masalah baik secara kualitatif maupun kuantitatif.

Agar tercapainya hal tersebut maka diperlukan proses pembelajaran yang dapat memfasilitasi siswa mencapai tujuan pembelajaran tersebut. Berdasarkan Permendiknas Nomor 41 Tahun 2007 tentang standar proses pendidikan disebutkan bahwa "mengingat kebhinekaan budaya, keragaman latar belakang dan karakteristik peserta didik, serta tuntutan untuk menghasilkan lulusan yang bermutu, proses pembelajaran untuk setiap mata pelajaran harus fleksibel, bervariasi, dan memenuhi standar". Oleh karena itu guru yang mengajar harus mampu menjadi fasilitator agar pembelajaran di sekolah dapat dilakukan secara interaktif, menyenangkan, menantang, dan memotivasi peserta didik untuk aktif dalam pembelajaran sehingga pembelajaran terpusat kepada siswa (student centered) (2).

Taksonomi Bloom yang telah direvisi menjelaskan bahwa proses kognitif terbagi menjadi dua kategori yaitu kemampuan berpikir tingkat rendah atau Lower Order Thinking Skills (LOT) dan kemampuan berpikir tingkat tinggi atau Higher Order Thinking Skills (HOTS). Kemampuan mengingat (remember), memahami (understand), dan menerapkan (apply) termasuk dalam kategori LOTS sedangkan kemampuan menganalisis (analyze), mengevaluasi (evaluate), dan menciptakan (create) termasuk kategori HOTS (3). Keterampilan berpikir tingkat tinggi (HOTS) menurut Resnick (1987) adalah "proses berpikir kompleks dalam menguraikan materi, membuat kesimpulan, membangun representasi, menganalisis, dan membangun hubungan dengan melibatkan aktivitas mental yang paling dasar.

Pada proses pembelajaran fisika di sekolah sebaiknya guru memfasilitasi agar keterampilan berpikir tingkat tinggi siswa bisa dilatihkan dan dibentuk secara baik untuk kemajuan hasil belajar yang diperoleh oleh siswa. Salah satu cara yang yang dapat dilakukan guru adalah dengan memilih dan menerapkan model, metode, strategi dan media pembelajaran yang tepat saat pembelajarn fisika berlangsung. Pengguanaan media pembelajaran diharapkan mampu mempermudah guru dalam memberikan materi pelajaran sehingga peserta didik mendapatkan hasil belajar yang maksimal.

Salah satu media yang dapat digunakan dalam pembelajaran adalah simulasi virtual. Berdasarkan kamus besar bahasa Indonesia simulasi diartikan sebagai penggambaran suatu sistem atau proses dengan peragaan berupa model statistik atau pemeranan. Sedangkan virtual artinya adalah tidak nyata. Sehingga dapat disimpulkan bahwa simulasi virtual adalah penggambaran suatu sistem atau proses melalui peragaan atau pemeranan yang dilakukan secara tidak nyata. Pada proses pembelajaran Simulasi virtual dapat dilakukan dengan bantuan komputer untuk menjelaskan dan menyajikan materi-materi yang sulit disajikan didepan kelas seperti fenomena-fenomena alam, benda-benda dan materi mikroskopis dan makroskopis, peristiwa-peristiwa lain yang sulit disajikan secara nyata serta aktifitas-aktifitas lain yang dapat menimbulkan bahaya jika disajikan di kelas.

Dengan adanya simulasi virtual maka hal tersebut dapat disajikan di depan kelas melalui bantuan multimedia komputer sehingga proses pembelajaran menjadi lebih nyata, menarik dan menumbuhkan antusias siswa dalam menggali informasi yang diperlukan demi tercapainya tujuan pembelajaran. Pada pembelajaran fisika media simulasi virtual sangat dibutuhkan dalam membantu guru menyajikan materi pembelajaran karena materi ajar dalam pembelajaran fisika banyak yang bersifat mikroskopis dan makroskopis, artinya materi tersebut sulit divisualkan secara nyata saat proses pembelajaran, namun dengan adanya bantuan simulasi virtual kesulitan itu dapat diatasi dengan membuat sistem visual yang dapat menyerupai kenyataan. Selain itu "penggunaan multimedia memungkinkan guru dan siswa untuk mengintegrasikan, menggabungkan dan berinteraksi dengan media untuk mendukung proses pembelajaran yang akan dilaksanakan" (4). 
Penggunaan media simulasi virtual bertujuan untuk lebih menekankan demontrasi oleh guru dan siswa. Salah satu cabang IPA yang merupakan "kumpulan pengetahuan yang berupa faktafakta, konsep-konsep atau prinsip-prinsip serta merupakan proses penemuan adalah fisika. Berdasarkan hal tersebut, hakikat pembelajaran fisika penting untuk ditingkatkan adalah penguasaan konsep" (10).

Penggunaan simulasi virtual dalam proses pembelajaran juga dapat digunakan dalam memberikan solusi terhadap kegiatan praktikum di laboratorium yang memiliki masalah dengan alat dan bahan eksperimen. Percobaan dapat dilakukan secara virtual menggunakan laboratorium virtual. Penggunaan simulasi virtual dalam pembelajaran fisika selain dapat memudahkan guru menyajikan materi pembelajaran juga dapat meningkatkan keterampilan berpikir tingkat tinggi siswa karena dengan adanya simulasi virtual siswa dapat membangun kemampuan analisis, berpikir kompleks, menghubungkan varibael, menguraikan materi dan membuat kesimpulan. Selain itu, guru dapat menjelaskan dengan mudah materi yang dianggap sulit dan kompleks, sehingga pembelajaran fisika tidak lagi dianggap sulit oleh peserta didik.

Penelitian yang telah dilakukan oleh Andriyani Hastuti, Hairunnisyah Sahidu, dan Gunawan mendapatkan hasil bahwa model pembelajaran Problem Based Learning berbantuan media virtual berpengaruh terhadap penguasaan konsep fisika peserta didik. Dalam menerapkan model Problem Based Learning berbantuan media virtual yaitu guru mampu mengaitkan masalah-masalah dalam kehidupan sehari-hari dengan konsep fisika yang dipelajari (5).

Terdapat pada artikel lain yang diteliti oleh Syarifah Lely Fithriani, A. Halim, dan Ibnu Khaldun terdapat pengaruh dan peningkatan setelah menggunakan simulasi PhET terhadap keterampilan berfikir kritis. Kesimpulan yang didapatkan yaitu "Penggunaan media PhET ini dapat menumbuhkan berbagai macam pertanyaan oleh siswa, sehingga siswa mampu membuat hipotesis sampai dapat menemukan konsep yang menghubungkan dengan kehidupan sehari-hari. Sehingga dalam proses pembelajaran, siswa selalu dituntut untuk aktif dalam bertanya, mengevaluasi argument, membuat induksi, mendefinisikan istilah dan membuat keputusan" (6).

Berdasarkan penelitian-penelitian yang sudah ada, belum ditemukan penelitian yang melakukan kajian secara teoritis berupa literature review atau meta-analisis terkait dengan penggunaan simulasi virtual pada pembelajaran fisika. Penelitian ini penting dilakukan agar ditemukan landasan yang kuat tentang bagaimana keterkaitan penggunaan simulasi virtual pada pembelajaran fisika dengan hasil belajar siswa baik berupa pemahaman konsep, penguasaan konsep, keterampilan berpikir tingkat tinggi dan lain sebagainya. Selain itu, materi-materi pembelajaran fisika baik di SMA maupun di IPA SMP yang sudah diteliti menggunakan simulasi virtual perlu dianalisis agar diperoleh kesimpulan tentang materi apa yang paling sering digunakan, materi apa yang belum digunakan dan materi seperti apa yang karakternya cocok diajarkan menggunakan simulasi virtual.

Berdasarkan hal itu maka peneliti akan membahas pengguaan simulasi virtual pada pembelajaran fisika untuk meningkatkan Higher Order Thinking Skills (HOTS) yang dilihat dari rumusan masalah penelitian antara lain: (1) Jenis penelitian apa saja yang terkait dengan media simulasi virtual?; (2) Bagaimana indikator pencapaian yang digunakan dalam menerapkan media simulasi virtual?; (3) Materi apa saja yang digunakan pada penggunaan simulasi virtual?

\section{METODE PENELITIAN}

Penelitian ini menggunakan metode kuantitatif dengan desain meta-analisis. Penelitian meta-analisis adalah jenis penelitian survei yang termasuk ke dalam penelitian deskriptif. Pengumpulan data dilakukan dengan cara mengumpulkan, merangkum, dan menganalisis artikel yang berkaitan dengan penggunaan simulasi virtual untuk meningkatkan Higher Order Thinking Skills (HOTS) siswa pada pembelajaran fisika. Artikel jurnal yang dianalisis sebanyak 20 artikel yang diperoleh dari jurnal nasional terakreditasi sinta 1 hingga sinta 4 dan beberapa jurnal internasional bereputasi. Kemudian dilakukan klasifikasi berdasarkan jenis metode penelitian yang digunakan, variable terikat yang digunakan, dan materi yang digunakan sebagai konten dalam media simulasi yang diteliti. 
Tabel 1. Distribusi 20 Artikel Subjek Penelitian

\begin{tabular}{|c|c|c|c|c|}
\hline No. & Peneliti & Jenis Penelitian & Indikator Pencapaian & Materi \\
\hline 1. & Hastuti, Sahidu, \& & Quasi & Kemampuan & Tumbukan Dan Hukum \\
\hline & Gunawan, 2016 (5) & Experimen & Pemecahan Masalah & Kekekalan Momentum \\
\hline 2. & Arianti, Sahidu, Harjono, \& & $\begin{array}{l}\text { Quasi } \\
\text { Elcnerimen }\end{array}$ & Penguasaan Konsep & Laju Reaksi \\
\hline 3. & $\begin{array}{c}\text { Dewi, Harjono, \& Gunawan, } \\
2016 \text { (7) }\end{array}$ & $\begin{array}{l}\text { Quasi } \\
\text { Eksperimen }\end{array}$ & $\begin{array}{c}\text { Penguasaan Konsep dan } \\
\text { Kreativitas }\end{array}$ & $\begin{array}{l}\text { Aplikasi Gelombang } \\
\text { Elektromagnetik }\end{array}$ \\
\hline 4. & $\begin{array}{l}\text { Elita Dwi Sanyoto, Woro } \\
\text { Setyarsih, } 2016(8)\end{array}$ & $\begin{array}{l}\text { Pre- } \\
\text { Experimental } \\
\text { Design }\end{array}$ & Miskonsepsi & $\begin{array}{l}\text { Suhu, Kalor, Dan } \\
\text { Perpindahan Kalor }\end{array}$ \\
\hline 5. & $\begin{array}{c}\text { Famani, Ayub, \& Sudjito, } \\
2019(9)\end{array}$ & Deskripsi & Pemahaman Konsep & Hukum Induksi Faraday \\
\hline 6. & $\begin{array}{l}\text { Syarifah lely fithriani, a. } \\
\text { Halim dan ibnu khaldun }\end{array}$ & $\begin{array}{l}\text { Quasi } \\
\text { eksperimen }\end{array}$ & $\begin{array}{l}\text { Keterampilan } \\
\text { Berpikir kritis }\end{array}$ & Kalor \\
\hline 7. & $\begin{array}{l}\text { Hotman, Koto, \& Rohadi, } \\
2018 \text { (10) }\end{array}$ & $\begin{array}{l}\text { Quasi } \\
\text { eksperimen }\end{array}$ & $\begin{array}{c}\text { Kemampuan } \\
\text { pemecahan masalah }\end{array}$ & - \\
\hline 8. & Juniartini \& ..., 2017 (11) & $\begin{array}{l}\text { Quasi } \\
\text { Experiment }\end{array}$ & Pemahaman Konsep & Listrik Dinamis \\
\hline 9. & Kohar, 2017 (12) & $R \& D$ & Miskonsepsi & - \\
\hline 10. & $\begin{array}{l}\text { Khairun Niami. Kosim, } \\
2018 \text { (13) }\end{array}$ & $\begin{array}{c}\text { Quasi } \\
\text { Eksperimen }\end{array}$ & Penguasaan Konsep & Alat-Alat Optik \\
\hline 11. & $\begin{array}{c}\text { Nisa, Lesmono, \& Bachtiar, } \\
2018 \text { (14) }\end{array}$ & Eksperimen & $\begin{array}{l}\text { Kemampuan Berpikir } \\
\text { Kritis }\end{array}$ & $\begin{array}{l}\text { Momentum, Impuls Dan } \\
\text { Tumbukan }\end{array}$ \\
\hline 12. & $\begin{array}{c}\text { Nugroho \& Darmawan, } \\
2018(15)\end{array}$ & Eksperimen & Minat Belajar & $\begin{array}{c}\text { Gerak } \\
\text { Harmonis Sederhana }\end{array}$ \\
\hline 13. & $\begin{array}{l}\text { Suranti, Gunawan, \& } \\
\text { Sahidu, } 2016 \text { (16) }\end{array}$ & $\begin{array}{c}\text { Quasi } \\
\text { Eksperimen }\end{array}$ & $\begin{array}{l}\text { Penguasaan } \\
\text { Konsep }\end{array}$ & Alat-alat Optik \\
\hline 14. & $\begin{array}{l}\text { Rais, Hakim, \& Sulistiawati, } \\
2020 \text { (17) }\end{array}$ & $\begin{array}{c}\text { Quasi } \\
\text { Eksperimen }\end{array}$ & Pemahaman Konsep & Elastisitas \\
\hline 15. & $\begin{array}{l}\text { Riwayani, Perdana, Sari, } \\
\text { Jumadi, \& Kuswanto, } 2019 \\
\text { (18). }\end{array}$ & Mixed Method & $\begin{array}{c}\text { Kemampuan } \\
\text { Argumentasi Ilmiah }\end{array}$ & Optik \\
\hline 16. & $\begin{array}{l}\text { (Fithriani, Halim, \& } \\
\text { Khaldun, } 2016 \text { (6) }\end{array}$ & $\begin{array}{c}\text { Quasi } \\
\text { Eksperiment }\end{array}$ & Hasil Belajar & Elastisitas \\
\hline 17. & Siti, Aris \& Hikmawati & $\begin{array}{l}\text { Quasi } \\
\text { Experiment }\end{array}$ & Penguasaan Konsep & Fluida Dinamis \\
\hline 18. & $\begin{array}{c}\text { Wibowo \& Iswanto, } 2019 \\
\text { (19) }\end{array}$ & Mixed Method & Pemahaman Konsep & Kelistrikan \\
\hline 19. & $\begin{array}{c}\text { Firmanul Catur WIBOWO. } \\
\text { dkk., } 2017 \text { (20) }\end{array}$ & $\begin{array}{l}\text { Kualitatif \& } \\
\text { Kuantitatif }\end{array}$ & Perubahan Konseptual & Perpindahan Panas \\
\hline 20 & $\begin{array}{c}\text { Suci Prihatiningtyas. Tjipto } \\
\text { Prastowo. Budi Jatmiko, } \\
2012(21)\end{array}$ & $R \& D$ & $\begin{array}{l}\text { Keterampilan } \\
\text { Psikomotor dan } \\
\text { Afektif }\end{array}$ & Alat Optik \\
\hline
\end{tabular}

\section{HASIL DAN PEMBAHASAN} berikut :

Hasil dari data penelitian yang dimasukkan dalam penelitian meta-analisis ini adalah sebagai

Tabel 2. Jenis Penelitian

\begin{tabular}{clccc}
\hline No & \multicolumn{1}{c}{ Jenis Penelitian } & Frekuensi & Frekuensi Relatif \\
\hline 1. & Quasi Experimen, Eksperimen, dan & Pre- & 14 & $70 \%$ \\
& Experimental & & & \\
2. & Mix-Method & & 2 & $10 \%$ \\
3. & $R \& D$ & 1 & $10 \%$ \\
4. & Kualitatif \& Kuantitatif & & $5 \%$
\end{tabular}

Penggunaan Simulasi Virtual pada Pembelajaran Fisika untuk Meningkatkan Higher Order Thinking Skills (HOTS) Siswa : Meta.... Miftahul Khirana Anisa, Niki Dian Permana P, Theresia Lidya Nova 


\begin{tabular}{|c|c|c|c|}
\hline No & Jenis Penelitian & Frekuensi & Frekuensi Relatif \\
\hline & Deskripstif & 1 & $5 \%$ \\
\hline
\end{tabular}

Pada Tabel 2. terlihat bahwa jenis penelitian yang digunakan peneliti pada artikel jurnal yang dianalisis adalah quasi experimen, experimen, pre experimental, mix-methode, research and development (R\&D), kualitatif dan kuantitatif, serta metode deskriptif. Berdasarkan analisis data diperoleh bahwa jenis penelitian yang paling banyak dilakukan adalah jenis penelitian quasi experimen, experiment dan pre-experimental dengan frekuensi relative $70 \%$. Untuk jenis penelitian mix-methode dan R\&D diperoleh frekuensi masing-masing sebesar 10\%. Penelitian R\&D biasanya dilakukan untuk proses perancangan dan pengembangan simulasi virtual yang digunakan untuk pembelajaran. Sedangkan jenis penelitian yang paling sedikit dilakukan adalah jenis penelitian kualitatif \& kuantitatif serta penelitian deskriptif dengan frekuensi masing-masing 5\%. Secara umum dapat dilihat bahwa jenis penelitian yang digunakan pada penelitian penggunaan simulasi virtual pada pembelajaran fisika merupakan termasuk dalam metode eksperimen.

Penelitian penggunaan simulasi virtual banyak dilakukan dengan menggunakan metode eksperimen karena metode penelitian ini sangat cocok dan sesuai untuk diaplikasikan dalam menguji pengaruhnya terhadap indikator pencapaian atau variable terikat yang berkaitan dengan hasil belajar kognitif peserta didik baik berupa pemahaman konsep, penguasaan konsep, keterampilan berpikir kritis, keterampilan berpikir kreatif, kemampuan pemecahan masalah, keterampilan berpikir tingkat tinggi dan lain-lain.

Adapun hasil analisis yang berkaitan dengan indikator pencapaian pada artikel jurnal yang diteliti dapat dilihat pada tabel berikut.

Tabel 3. Indikator Pencapaian

\begin{tabular}{llcc}
\hline No. & Indikator Pencapaian & Frekuensi & Frekuensi Relatif \\
\hline 1. & Penguasaan Konsep & 5 & $25 \%$ \\
2. & Pemahaman Konsep & 4 & $20 \%$ \\
3. & Keterampilan Berpikir kritis & 2 & $10 \%$ \\
4. & Kemampuan Pemecahan Masalah & 2 & $10 \%$ \\
5. & Miskonsepsi (Reduksi) & 2 & $10 \%$ \\
6. & Kemampuan Argumentasi Ilmiah & 1 & $5 \%$ \\
7. & Keterampilan Psikomotor dan Afektif & 1 & $5 \%$ \\
8. & Perubahan Konseptual & 1 & $5 \%$ \\
9. & Hasil Belajar & 1 & $5 \%$ \\
10. & Minat Belajar & 1 & $5 \%$ \\
\hline
\end{tabular}

Pada Tabel 3. terlihat bahwa indikator pencapaian yang diteliti sebagai variabel terikat pada artikel jurnal yang dianalisis adalah penguasaan konsep, pemahaman konsep, keterampilan berpikir kritis, kemampuan pemecahan masalah, reduksi miskonsepsi, kemampuan argumentasi ilmiah, keterampilan psikomotor dan afektif, perubahan konseptual, hasil belajar dan minat belajar.

Indikator pencapaian yang paling banyak digunakan sebagai variabel terikat pada penelitian adalah penguasaan konsep dengan frekuensi 25\%. Sedangkan untuk keterampilan berpikir kritis, kemampuan pemecahan masalah, dan reduksi miskonsepsi yang kesemuanya itu dapat digolongkan dalam keterampilan berpikir tingkat tinggi jika dipresentasekan adalah sebesar $30 \%$.

Adapun materi-materi pembelajaran fisika yang yang diajarkan menggunakan simulasi virtual pada artikel jurnal penelitian yang dianalisis secara rinci dapat dilihat pada tabel berikut

Tabel 4. Materi Pembelajaran

\begin{tabular}{llrc}
\hline No & Materi & Frekuensi & Frekuensi Relatif \\
\hline 1. & Optik dan Alat-alatnya & 4 & $20 \%$ \\
2. & Momentum dan Impuls & 2 & $10 \%$ \\
3. & Elastisitas & 2 & $10 \%$ \\
4. & Kelistrikan & 2 & $10 \%$ \\
5. & Kalor & 2 & $10 \%$ \\
6. & Laju Reaksi & 1 & $5 \%$
\end{tabular}




\begin{tabular}{llrc}
\hline No & Materi & Frekuensi & Frekuensi Relatif \\
\hline 7. & Fluida Dinamis & 1 & $5 \%$ \\
8. & Aplikasi Gelombang Elektromagnetik & 1 & $5 \%$ \\
9. & Perpindahan Panas & 1 & $5 \%$ \\
10. & Gerak Harmonis Sederhana & 1 & $5 \%$ \\
11. & Hukum Induksi Faraday & 1 & $5 \%$ \\
\hline
\end{tabular}

Berdasarkan data pada tabel 4 terlihat bahwa materi yang paling banyak diteliti dalam penggunaan simulasi virtual adalah materi optik dan alat-alatnya dengan frekuensi sebesar $20 \%$. Secara umum terlihat bahwa materi-materi fisika yang digunakan pada simulasi virtual merupakan materi yang bersifat mikroskopis sehingga dibutuhkan bantuan simulasi virtual untuk menyajikannya agar terlihat seperti nyata saat diajarkan di kelas. Pada materi optik dan alat-alatnya, simulasi virtual sangat dibutuhkan untuk memvisualisasikan berkas sinar atau cahaya dalam proses pembentukan bayangan dari benda. Pada materi optik dan alat-alatnya simulasi yang digunakan banyak menerapkan sub materi mata dan kamera (16) dan dilihat dari indikator pencapaiannya penguasaan konseplah yang sering digunakan pada media ini.

Pada umumnya media simulasi virtual sangat membantu proses pembelajaran yang berbasis praktikum maupun yang tidak karena dengan adanya simulasi virtual peserta didik dapat belajar dengan mudah dalam memahami materi yang telah dipelajari (7).

Penggunaan simulasi virtual dalam dunia pendidikan sangat dibutuhkan untuk menjelaskan suatu materi atau problem yang sulit dipahami peserta didik jika tidak menggunakan alat peraga karena dengan adanya simulasi dapat menjadi perwujudan contoh yang seharusnya dilakukan. Simulasi virtual sangat bermanfaat digunakan untuk menjelaskan suatu hubungan variable yang rumit tentang suatu materi ajar sehingga dapat meningkatkan keterlibatan peserta didik secara aktif menemukan konsep dan pengetahuannya dalam pembelajaran. Selain itu, simulasi virtual dapat menjelaskan dan merealisasikan fenomena atau konsep materi yang abstrak menjadi nyata, membantu menjelaskan materi yang dapat membangkitkan proses belajar aktif, membiasakan peserta didik untuk dapat berpikir kreatif dan kritis, meningkatkan keterampilan berpikir tingkat tinggi, meningkatkan minat belajar siswa dan meningkatkan retensi peserta didik dengan baik.

Keterampilan berpikir tingkat tinggi dapat terkontruksi dengan baik melalui bantuan simulasi virtual pada proses pembelajaran karena peserta didik dapat membangun dan menemukan sendiri konsep pengetahuannya dengan mengkaitkan pengetahuan awal yang dimilikinya dengan visualisasi yang terdapat pada simulasi virtual.

\section{SIMPULAN DAN SARAN}

Berdasarkan hasil dan pembahasan di atas dapat disimpulkan : (1) metode penelitian yang banyak digunakan dalam menerapkan media simulasi virtual yaitu metode quasi experimen (2) indikator pencapaian yang banyak diteliti dalam penerapan media simulasi virtual yaitu penguasaan konsep (3) materi pembelajaran fisika yang banyak digunakan dalam penerapan media simulasi virtual adalah materi optik dan alat-alatnya. (4) Penggunaan media simulasi virtual pada pembelajaran fisika dapat meningkatkan keterampilan berpikir tingkat tinggi siswa.

\section{DAFTAR PUSTAKA}

1. Kementerian Pendidikan dan Kebudayaan. Peraturan Menteri Pendidikan Dan Kebudayaan Nomor 22 Tahun 2016 Tentang Standar Proses Pendidikan Dasar Dan Menengah. Indonesia; 2016.

2. Permana ND, Hamidah I, Setiawan A. Penggunaan Website dalam Penerapan Model Pembelajaran Learning Cycle 7E untuk Meningkatkan Pemahaman Konsep Siswa pada Materi Kinematika Gerak Lurus. Gravity J Ilm Penelit dan Pembelajaran Fis. 2015;1(1):110 . 
3. Direktorat Jendral Guru dan Tenaga Kependidikan. Buku Pegangan Keterampilan Berpikir Tingkat Tinggi Berbasi Zonasi. 2018.

4. Arianti BI, Sahidu H, Harjono A, Gunawan G. Pengaruh Model Direct Instruction Berbantuan Simulasi Virtual Terhadap Penguasaan Konsep Siswa. J Pendidik Fis dan Teknol. 2016;2(4):159-63.

5. Hastuti A, Sahidu H, Gunawan G. Pengaruh Model PBL Berbantuan Media Virtual Tehadap Kemampuan Pemecahan Masalah Fisika. J Pendidik Fis dan Teknol. 2016;2(3):129-35.

6. Fithriani S, Halim A, Khaldun I. Penggunaan Media Simulasi Phet Dengan Pendekatan Inkuiri Terbimbing Untuk Meningkatkan Keterampilan Berpikir Kritis Siswa Pada Pokok Bahasan Kalor di SMA Negeri 12 Banda Aceh. J Pendidik Sains Indones. 2016;4(2):45-52.

7. Dewi SM, Harjono A, Gunawan G. Pengaruh Model Pembelajaran Berbasis Masalah Berbantuan Simulasi Virtual Terhadap Penguasaan Konsep dan Kreativitas Fisika Siswa SMAN 2 Mataram. J Pendidik Fis dan Teknol. 2016;2(3):123-8.

8. Elita Dwi Sanyoto, Woro Setyarsih AK. Penerapan Model Pembelajaran Interactive Demonstration Berbantuan Media Simulasi Virtual Untuk Mengurangi Miskonsepsi Siswa Pada Materi Suhu, Kalor, Dan Perpindahan Kalor. J Inov Pendidik Fis. 2016;05(03):188-92.

9. Famani STM, Ayub MRSSN, Sudjito DN. Physics Learning Design of Faraday's Induction Law Material Using phet Simulation. J Pendidik Fis Indones. 2019;15(2):87-96.

10. Hotman RS, Koto I, Rohadi N. Pengaruh Pembelajaran Cooperative Problem Solving Berbantuan Media Virtual Phet terhadap Motivasi Berprestasi dan Kemampuan Pemecahan Masalah Fisika Siswa Kelas X MIPA SMAN 1 Bengkulu Selatan. J Kumparan Fis. 2018;1(3):51-6.

11. Juniartini NW, ... Pengaruh Model Pembelajaran Perubahan Konseptual Berbantuan Simulasi Phet Untuk Meningkatkan Pemahaman Konsep Fisika .... J Pendidik Fis ... 2017;7(2):109_ 19.

12. Kohar SBJR. Pengembangan Perangkat Pembelajaran Berbasis Inkuiri Terbimbing Menggunakan Simulasi Phet Untuk Mereduksi Miskonsepsi Siswa. 2017;6(2):1289-301.

13. Khairun Niami. Kosim G. Model Problem Based Learning Berbantuan Simulasi Komputer Untuk Meningkatkan Penguasaan Konsep Pada Materi Alat-Alat Optik. J Pendidik Fis dan Teknol. 2018;4(2):220-5.

14. Nisa FC, Lesmono AD, Bachtiar RW. Model Pembelajaran Kontekstual Relating, Experiencing, Applying, Cooperating, and Transferring (React) Dengan Simulasi Virtual Dalam Pembelajaran Fisika Di Sma (Materi Momentum, Impuls Dan Tumbukan Kelas X Sman 2 Jember). J Pembelajaran Fis. 2018;7(1):8.

15. Nugroho CH, Darmawan H. Penerapan Model Pembelajaran Novick Menggunakan Media Riil Dan Media Simulasi Virtual Ditinjau Dari Harmonis Sederhana Kelas X Sman 1 Kembayan. J Prodi Pendidik Fis. 2018;05(1):hal. 4.

16. Suranti NMY, Gunawan G, Sahidu H. Pengaruh Model Project Based Learning Berbantuan Media Virtual Terhadap Penguasaan Konsep Peserta didik pada Materi Alat-alat Optik. J Pendidik Fis dan Teknol. 2016;2(2):73-9.

17. Rais AA, Hakim L, Sulistiawati S. Pemahaman Konsep Siswa melalui Model Inkuiri Terbimbing Berbantuan Simulasi phet. Phys Educ Res J. 2020;2(1):1.

18. Riwayani R, Perdana R, Sari R, Jumadi J, Kuswanto H. Analisis kemampuan argumentasi ilmiah siswa pada materi optik: Problem- based learning berbantuan edu-media simulation. $\mathrm{J}$ Inov Pendidik IPA. 2019;5(1):45-53. 
19. Wibowo FC, Iswanto BH. Designing MOOCS with Virtual Microscopic Simulation (VMS) for increasing of student's levels of understanding. J Phys Conf Ser. 2019;1402(6).

20. Firmanul Catur Wibowo. Dkk. Virtual Microscopic Simulation (VMS) to promote students' conceptual change: A case study of heat transfer. 2017;18(2).

21. Suci Prihatiningtyas. Tjipto Prastowo. Budi Jatmiko. Pengembangan Perangkat Pembelajaran Fisika Smp Berbasis Simulasi Virtual Dan Kit Sederhana Dengan Model Pembelajaran Langsung Dan Kooperatif Untuk Mengajarkan Keterampilan Psikomotor Dan Afektif Pada Pokok Bahasan Alat Optik. Pendidik Sains Pascasarj Univ Negeri Surabaya. 2012;2(1):13541. 